\title{
Understanding the Method Effects of the Ethnic Identity Scale Items
}

\author{
Qothrun Nada*1, Sukaesi Marianti ${ }^{2}$ \\ ${ }^{1}$ Faculty of Psychology, Universitas Airlangga Surabaya, ${ }^{2}$ Department of Psychology, Faculty of Social and \\ Political Sciences, Universitas Brawijaya
}

Submission 17 February 2021 Accepted 11 October 2021 Published 24 December 2021

\begin{abstract}
This study useds the Correlated Traits-Correlated Method (CTCM) model to identify the method effects of the Ethnic Identity Scale (EIS) items, both in favorable and unfavorable items. The study involved 4 alternative models of the CTCM to test the suitability of the model. 440 secondary-school students were involved in this study. Confirmatory Factor Analysis was used employing $\mathrm{R}$ software Version 4.0.2. Results indicated alignments between the data with three CTCM alternative models that provided evidence to understand the effect of the method on the use of positive and negative items that could affect the validity of a measuring instrument.
\end{abstract}

Keywords: confirmatory factor analysis; correlated traits-correlated methods; method effect; positive and negative items

Every psychological instrument has its own method of measuring psychological constructs (Fiske, 1982). According to Widhiarso (2017) method holds a vast meaning in the concept of psychological measurement. According to Fiske (1982) method has a broad meaning due to containing several aspects: content item, response format, general instruction or administrative measurement, and characteristics of the respondents.

Campbell and Fiske (1959) proposed a method of testing validity using Multitrait-Multimethod Design (MTMM) to address the diverse definition of methods. MTMM is a tool used to measure traits or constructs measured through different methods (Campbell \& Fiske, 1959). Pohl et al. (2007) argue that this approach was used in response to cases wherein a measurement tool using several methods for the same construct resulted in different results, threatening the validity of the measurement tool.

One aspect that could threaten the validity of a measurement tool is the method effect (Lindwall et al., 2012). According to Lindwall et al. (2012), method effects refer to the tendency for participants to respond to a questionnaire based on other criteria outside of the intended construct, causing some variance that are irrelevant to what the scale is meant to measure. In his study, Widhiarso (2017) found that one of the sources of method effect is the use of positive (favorable) and negative (unfavorable) items.

Positive and negative items refer to the different directions in which an item is used within a psychological measurement tool. Positive direction is typically called favorable items, and conversely, negative direction is known as unfavorable item (Widhiarso, 2017). Positive and negative items

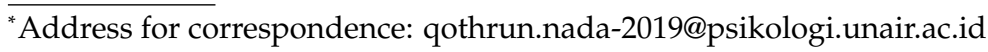


are commonly found in psychological measurement tools to reduce the possibility of response bias (DeVellis, 2016). Unfavorable items further aim to help respondents to be more aware when responding to items being measured (Widhiarso, 2016).

General assumption on the use of positive and negative items in a psychological measurement scale is to measure the same construct through different methods (Marsh, 1996). However, if the response does not meet these assumptions, it will result in the emergence of method effects (DiStefano $\&$ W., 2006). Method effects in negative and positive items has a couple of implications. First, changing the factor structure because positive and negative items formed a separate factor outside the original construct, affecting the validity of the construct (DiStefano \& W., 2006; Vinet \& Zhedanov, 2011; Widhiarso, 2016). Second, it should be noted that the method effect can affect the interpretation of the measurement scale (DiStefano \& W., 2006).

This study aims to determine the method effects of using positive and negative items to seek answers to the above-mentioned problem. Several previous studies have found that the use of positive and negative items has shown to cause method effects (de Lima \& de Souza, 2019; DiStefano \& W., 2006; Lindwall et al., 2012; Marsh, 1996; Motl \& DiStefano, 2002; Rodrigo et al., 2019; Tomás et al., 2013). In Indonesia, research on the use of positive and negative items in 2016 found that negative items formed a separate factor (Widhiarso, 2016). Widhiarso (2017) also found a consistent result, that is using positive and negative items could result in a method effect.

One way to discover method effects in positive and negative items is through Confirmatory Factor Analysis (CFA) (de Lima \& de Souza, 2019). CFA was carried out in several studies to determine the existence of method effects (de Lima \& de Souza, 2019; DiStefano \& W., 2006; Lindwall et al., 2012; Marsh, 1996; Motl \& DiStefano, 2002; Rodrigo et al., 2019; Tomás et al., 2013). Through CFA, a method developed from MTMM, it becomes possible to separate the variance of constructs and methods (i.e., positive and negative items) (Lindwall et al., 2012). In his research, Widhiarso (2017) analyzed several approaches, including the Correlated Traits-Correlated Methods (CTCM) and Correlated Traits-Correlated Uniquenesses (CTCU).

This study focuses on the use of the CTCM approach. Specifically, we correlate between constructs/dimensions and methods (i.e., positive and negative items) through the CTCM. The CTCM model assumes that the construct and method are not correlated (Widhiarso, 2017). This study will develop four alternative models of CTCM to determine the existence of the method effect on each proposed model. Several studies conducted tests using several models such as Correlated Traits-Correlated Methods (CTCM) and Correlated Traits-Correlated Uniquenesses (CTCU) in one measuring instrument (de Lima \& de Souza, 2019; DiStefano \& W., 2006; Lindwall et al., 2012; Tomás et al., 2013; Widhiarso, 2017). This study chose to use only the CTCM model because it could determine the variance related to indicators, constructs of measure, constructs of methods, and residuals (Widhiarso, 2017). As such, this approach is expected to provide evidence-based information on the use of statistical approaches in identifying the existence of method effects in the use of positive and negative items.

The instrument used in this study is the Ethnic Identity Scale (EIS) which Umaña-Taylor and 
Shin (2007) (Umaña-Taylor \& Shin, 2007). The selection of the EIS scale in this study was due to the lack of research on method effects other than in the Rosenberg Self Esteem (RSE) scale (de Lima \& de Souza, 2019; DiStefano \& Motl, 2009a; DiStefano \& W., 2006; Greenberger et al., 2003; Lindwall et al., 2012; Marsh et al., 2010; Tomás et al., 2013). Meanwhile, the method effects were found on other scales such as social physique anxiety (Molt \& Conroy, 2000) and the self-esteem scale or Coopersmith Self Esteem Inventory (CSEI) (Widhiarso, 2017).

Based on the above review, the emergence of method effects from positive and negative items needs to be controlled because the former can become a systematic error that interferes with research interpretation or conclusions (Campbell \& Fiske, 1959). Therefore, the purpose of this study was to determine the existence of method effects in the use of positive and negative items on the Ethnic Identity Scale (EIS) scale. The results of this study can contribute to psychological science, especially in psychometrics related to the effects of methods in the use of positive and negative items and the use of CTCM.

\section{Method}

\section{Research Participants}

Participants of this research were high school students in Malang aged 15 to 18 years. This age group was chosen because identity-seeking behaviour is prominent at this stage, as proposed by Phinney (1992). We used non-probability sampling as the primary sampling technique, with the support of the school to select the participants. Approval to conduct this research was obtained from the respective ethics committees of the university and school that were involved in the research. Students were recruited from one high school in Malang and every student agreed was assessed. In total, 442 students in $10^{\text {th }}$ and $11^{\text {th }}$ grades were involved in this research. The selected respondents were given an explanation about the research procedure to complete the EIS scale.

\section{Research Instrument}

EIS was initially constructed by Umaña-Taylor (2004) and was later adapted from English to Indonesian by Paramita (2014). The research conducted by Paramita et al. (2014) with Javanese and Chinese teenagers resulted in the reliability of 0.84 for the exploration dimension, 0.76 for the commitment dimension, and 0.88 for the affirmation dimension. The EIS scale has also been studied by Azzahrah (2017), who tested the reliability of the EIS scale by using the coefficient of stability and equivalence for junior high school students and yielded scores of $0.73,0.70$, and 0.74 on the dimensions of exploration, commitment, and affirmation (Azzahrah, 2017).

The EIS consists of 17 items that measure three dimensions: exploration, commitment, and affirmation. The nature of the EIS is multidimensional and uncorrelated because the three dimensions (i.e., exploration, commitment, and affirmation) do not have correlations (Umaña-Taylor, 2004). EIS has positive and negative items and uses a Likert scale with four responses as follows: 1) Strongly Disagree 2) Disagree, 3) Agree, 4) Strongly Agree. The score value is given from 1 (Strongly Disagree) 
to 4 (Strongly Agree). For negative items, the score value is reversed.

\section{Data Analysis Approach}

Data analysis was carried out using CFA with the help of the R program software version 4.0.2 with the lavaan package. CFA analysis was conducted to test the effects of the EIS scale method. Before testing the model with CTCM, an analysis was carried out on the original structure of the EIS. The next step is to analyze the method effects using the CTCM approach, developed into four alternative models (see Figure 1).

\section{Figure 1}

5 models of EIS. E=Exploration. $C=$ Commitment. $A=$ Affirmation. $P=$ Positive Item. $N=$ Negative Item
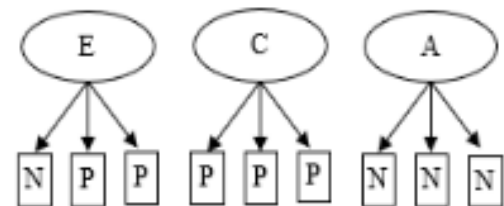

1) Model 1

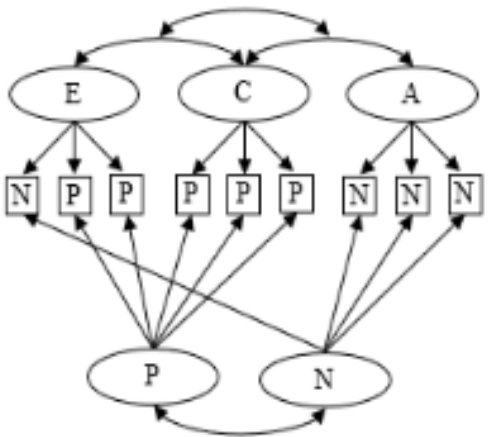

2) Model 2

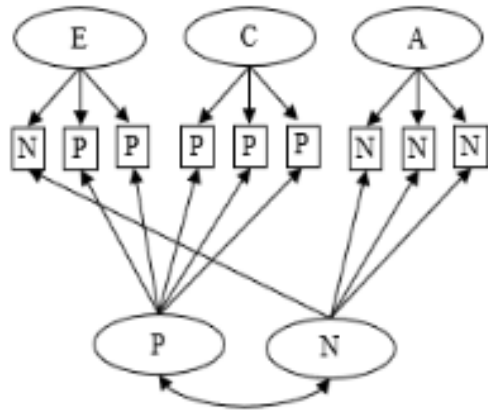

4) Model 4

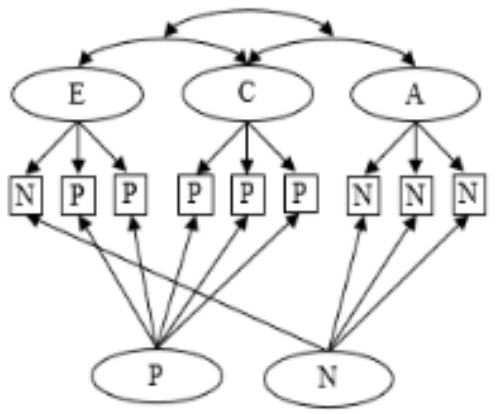

3) Model 3

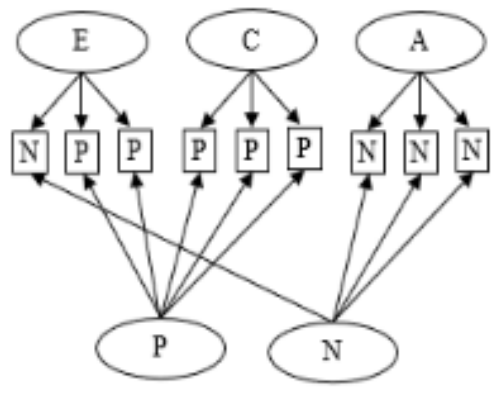

5) Model 5

Figure 2

Figure 1. 5 models of EIS. $\mathrm{E}=$ Exploration. $\mathrm{C}=$ Commitment. $\mathrm{A}=$ Affirmation. $\mathrm{P}=$ Positive Item. $\mathrm{N}=$ Negative Item. 
Model 1 is the model developed from the original structure of EIS. Model 2 is the Correlated Traits-Correlated Methods (CTCM) developed to determine method effects by correlating between methods (i.e., positive and negative items) and between dimensions of EIS. Model 3 used the Correlated Trait Uncorrelated Methods (CTUM) to test method effects by correlating the three dimensions of EIS but not between methods. Model 4 used the Uncorrelated Trait Correlated Method (UTCM), which tests method effect by correlating the positive and negative item method but not between EIS dimensions. Lastly, model 5 is the Uncorrelated Trait Uncorrelated Method (UTUM) developed to determine the method effect when no correlation is done between the three dimensions and methods (i.e., positive and negative items).

All the models are analyzed using an estimated model, namely Weighted Least Square Mean and Variance Corrected (WLSMV). In the R program, WLSMV is similar to the Diagonally Weighted Least Square (DWLS). Several criteria measure the level of fit of the model according to Hair et al. (2009), namely, 0.08 for the Root Mean Square Error of Approximation (RMSEA), then $>.95$ for the Comparative fit index (CFI) and the Tucker-Lewis Index (TLI) and $<.08$ for Standardized Root Mean Square Residual (SRMR).

\section{Result}

\section{Descriptive Statistics}

Due to incomplete answers, two participants were deleted. In total, data from 440 high school students (grade 10 and 11) from Malang were eligible to be analyzed in this study. The average age of the respondents was \pm 16.1 . The data that passed for analysis consisted of $56 \%$ grade 10 and $44 \%$ grade 11 ; as many as $42 \%$ were male and $58 \%$ female. $96 \%$ of respondents are Javanese, and $4 \%$ are other ethnic groups such as Balinese, Dayak, Madurese, Arabic, Malay, and Tenggerese.

\section{Model Testing}

Table 1 depicts the results of testing method effects on positive and negative items using Confirmatory Factor Analysis (CFA).

\section{Table 1}

The model-fit index of the five models

\begin{tabular}{ccccc}
\hline & \multicolumn{4}{c}{ Fit Indexes } \\
\cline { 2 - 5 } Model & CFI & TLI & RMSEA & SRMR \\
\hline Model 1 & .625 & .572 & .174 & .217 \\
Model 2 & .983 & .976 & .041 & .045 \\
Model 3 & .971 & .960 & .053 & .053 \\
Model 4 & .970 & .959 & .054 & .049 \\
Model 5 & .803 & .737 & .0137 & .159
\end{tabular}


Based on the five models that have been analyzed, the model fit is shown in model 2 (CTCM), model 3 (CTUM), and model 4 (UTCM). Model 2 (CTCM), model 3 (CTUM), and model 4 (UTCM) met the criteria for model fit because they met the criteria for values $>.95$ for CFI and TLI,.08 for RMSEA, and values $<.08$ for SRMR. Meanwhile, model 1 and model 5 do not meet the criteria for the model's fit based on the criteria determined.

The next step is to do a factor loading analysis on the model with the best fit, namely model 2 (CTCM). Based on Table 2, it appears that the results of the factor loading of the method factors show significant data $(p>05)$, indicating that there is a method effect when using positive and negative items.

Table 2

Factor Loading Result from CTCM

\begin{tabular}{|c|c|c|c|c|c|}
\hline \multirow[t]{2}{*}{ Item } & \multicolumn{5}{|c|}{ Correlated Trait Correlated Methods (CTCM) Model } \\
\hline & Exploration & Commitment & Affirmation & $\begin{array}{l}\text { Positive } \\
\text { Item }\end{array}$ & $\begin{array}{l}\text { Negative } \\
\text { Item }\end{array}$ \\
\hline Item $3^{\mathrm{a}}$ & & $0.30^{*}$ & & $.55^{*}$ & \\
\hline Item $4^{\text {a }}$ & $.17^{*}$ & & & $.50^{*}$ & \\
\hline Item $5^{\mathrm{a}}$ & $.54^{*}$ & & & $.29^{*}$ & \\
\hline Item $6^{\text {a }}$ & $.20^{*}$ & & & $.64^{*}$ & \\
\hline Item $8^{a}$ & $.52^{*}$ & & & $.50^{*}$ & \\
\hline Item $11^{\mathrm{a}}$ & $.13^{*}$ & & & $.66^{*}$ & \\
\hline Item $12^{\mathrm{a}}$ & & $.73^{*}$ & & $.31^{*}$ & \\
\hline Item $14^{\mathrm{a}}$ & & $.52^{*}$ & & $.35^{*}$ & \\
\hline Item $15^{\text {a }}$ & $.80^{*}$ & & & $.31^{*}$ & \\
\hline Item $17^{a}$ & & $.63^{*}$ & & $.40^{*}$ & \\
\hline Item $1^{\mathrm{b}}$ & & & $.15^{*}$ & & $.61^{*}$ \\
\hline Item $2^{b}$ & $.47^{*}$ & & & & $.41^{*}$ \\
\hline Item $7^{b}$ & & & $.15^{*}$ & & $.71^{*}$ \\
\hline Item $9^{b}$ & & & $.23^{*}$ & & $.44^{*}$ \\
\hline Item $10^{b}$ & & & $.60^{*}$ & & $.65^{*}$ \\
\hline Item $13^{b}$ & & & $.34^{*}$ & & $.68^{*}$ \\
\hline Item $16^{b}$ & & & $.50^{*}$ & & $.40^{*}$ \\
\hline
\end{tabular}

${ }^{\mathrm{a}}$ :positive item; ${ }^{\mathrm{b}}$ : negative item; ${ }^{*}: p>.05$

Another result obtained from the CTCM analysis is knowing the correlation value between dimensions/traits and between methods, namely positive and negative items, which can be seen in Table 3. 
Table 3

Correlation score between construct and methods

\begin{tabular}{lllllll}
\hline \multicolumn{1}{c}{ Model } & \multicolumn{5}{c}{ EIS } \\
\cline { 3 - 7 } & & $\mathbf{1}$ & $\mathbf{2}$ & $\mathbf{3}$ & $\mathbf{4}$ & $\mathbf{5}$ \\
\hline CTCM & 1. Exploration & 1 & & & & \\
& 2. Commitment & .54 & 1 & & & \\
& 3. Affirmation & .50 & .78 & 1 & & \\
& 4. Positive & - & - & - & 1 & - \\
& 5. Negative & - & - & - & .46 & - \\
\cline { 2 - 6 } & & & & &
\end{tabular}

The correlation results show a correlation value between dimensions with a range of .50 to .78 and a correlation value of .46 between positive and negative items.

\section{Discussion}

This study aimed to determine the existence of method effects on positive and negative items of EIS with CTCM analysis. Results of this study indicate a method effect resulting from the use of positive and negative items. The results are in line with other studies that prove the existence of method effects from the use of positive and negative items (de Lima \& de Souza, 2019; DiStefano \& W., 2006; Lindwall et al., 2012; Marsh, 1996; Motl \& DiStefano, 2002; Rodrigo et al., 2019; Tomás et al., 2013; Widhiarso, 2017). In addition, Table 1 shows that the results of the original structure of the EIS after the factor analysis did not meet the criteria of model fit if it did not involve positive and negative items as latent factors.

The current finding supports several past studies that uses RSE scale, which showed better model test results than the original structure of the RSE when positive and negative items were included in the method effect test (DiStefano \& W., 2006; Tomas \& Oliver, 1999; Tomás et al., 2013; Vinet \& Zhedanov, 2011). Another evidence of the method effect can be seen from the factor load analysis result of the EIS, where all items of the method factors show significance ( $p>0$.05). Only eight items from the construct factor have a factor loading greater than the method factor loading. These results strengthen the effect of method effects on the measuring construct of EIS.

In this study, the model that has the best fit in identifying method effects on the use of positive and negative items is CTCM. The results of this study are not in line with several previous studies which stated that negative items contributed to the existence of method effects (DiStefano \& Motl, 2009a; Lindwall et al., 2012; Marsh et al., 2010; Tomás et al., 2013; Y. Wu et al., 2016). However, several previous studies show that positive and negative items contribute to method effects (Lindwall et al., 2012; Marsh et al., 2010; Widhiarso, 2017; C.-H. Wu, 2008; Zeng et al., 2020).

There are several causes of method effects resulting from the use of negative items in this study. Some of them are due to inappropriate responses caused by respondents' carelessness when reading and understanding items and response bias (C.-H. Wu, 2008). Meanwhile, the existence of method effects on the positive items of this study can be explained because of the influence of the 
respondents' meaning and the influence of modesty bias which tends to be found in countries that prioritize collectivist orientation (C.-H. Wu, 2008). In this regard, the method effect on the positive items in this study is caused by the characteristics of the Indonesian respondents, with the majority of them being Javanese who tend to prioritize aspects of togetherness (Mangundjaya, 2013). The results of this study are in line with research conducted by Farh and Cheng (1997) and C.-H. Wu (2008) that the politeness bias in society with group orientation is more prominent on positive items $(\mathrm{C} . \mathrm{H}$. $\mathrm{Wu}$, 2008).

This study indicates that results from EIS are challenging to interpret due to the method effects of positive and negative items. Positive and negative items on this scale were assumed to be the same method. However, from the factor analysis and factor loading results, significant data are found in both methods. In addition, this study found that the factor loading of positive and negative items was not equivalent because the characteristics of negative items that typically do not support the construct (Widhiarso, 2016) had the opposite effect. This condition causes the method factor on the negative item to become an obstacle in interpreting the scale's accuracy.

Regarding the interpretation of the scale, researchers who use a scale with positive and negative items need to be careful when interpreting the results of the scale, especially if method effects are detected. This is because the method effect can measure a different construct from the contract to be measured (Widhiarso, 2017). In addition, citing the suggestion of C.-H. Wu (2008), method effects can be controlled without deleting items by performing Structural Equation Modeling (SEM) analysis to separate response constructs, methods, and variants, allowing results to be analyzed further with other variables in the same model.

This study not only proves the existence of method effects when using positive and negative items but also adds evidence of the usefulness of CTCM in detecting method effects, especially positive and negative items that have previously been carried out in several previous studies (Lindwall et al., 2012; Marsh et al., 2010; Widhiarso, 2017; C.-H. Wu, 2008; Zeng et al., 2020).

\section{Conclusion}

Our findings resulted in several conclusions. First, a method effect results from positive and negative items in a measuring instrument, especially in the EIS. Second, the method effect can be caused by carelessness in understanding items, response bias, and respondent characteristics. Third, CTCM has a good ability to identify the method effect of using positive and negative items. Fourth, the use of positive and negative items needs to be considered in a measurement instrument because it causes method effects and can disturb the measurement construct. However, suppose a researcher would like to incorporate positive and negative items, they need to control the method effect, one of which is by modeling through the CTCM approach. 
Nada \& Marianti || Understanding the Method Effects

\section{Recommendations}

Future researchers interested in a similar topic are advised to explore it using other approaches such as the Correlated Traits-Correlated Uniquenesses (CTCU). Additionally, future researchers can conduct invariant analysis with confirmatory multi groups based on demographic data such as gender because several studies show a relationship between gender and method effects (de Lima \& de Souza, 2019; DiStefano \& Motl, 2009b; Tomás et al., 2013).

\section{Declarations}

\section{Acknowledgments}

The author would like to thank those who helped carry out this research: Sukaesi Marianti, Putri Intan Larasati, Dhia Ulfah, Ayu Pratithi, Dera Kariema, Nur Musyahadah, Syavira SH, and other parties who cannot be mentioned.

\section{Author's Contribution}

QN is responsible for the manuscript's overall content, including preparing the original manuscript, conducting a literature review, data collection, and writing the manuscript. SM is responsible for conceptualizing research ideas, research instruments, providing literature reviews and research concepts.

\section{Funding}

The author(s) received no financial support for the research, authorship, and/or publication of this article

Conflict of Interests

The author(s) declared no potential conflicts of interest with respect to the research, authorship, and/or publication of this article.

Orcid ID

Qothrun Nada https:/ / orcid.org/0000-0002-3959-6193

Sukaesi Marianti https:/ / orcid.org/0000-0001-5775-0580

\section{References}

Azzahrah, F. (2017). Karakteristik psikometrik skala identitas etnis dilihat melalui pendekatan delayed alternate form pada remaja awal dan tengah [psychometric characteristics of the ethnic identity scale seen through a delayed alternate form approach in early and middle adolescents]. Universitas Brawijaya Malang. 
Campbell, D. T., \& Fiske, D. W. (1959). Convergent and discriminant validation by the multitrait-multimethod matrix. Psychological Bulletin, 56(2), 81-105. https://doi.org/10.1037/ h0046016

de Lima, T. J. S., \& de Souza, L. E. C. (2019). Rosenberg Self-Esteem Scale: Method effect and gender invariance. Psico-USF, 24(3), 517-528. https:/ / doi.org/10.1590/1413-82712019240309

DeVellis, R. F. (2016). Scale development theory and applications (fourth edition). SAGE Publication, 4 , 256.

DiStefano, C., \& Motl, R. W. (2009a). Personality correlates of method effects due to negatively worded items on the Rosenberg self-escale. Personality and Individual Differences, 46(3), 309-313. https: //doi.org/10.1016/j.paid.2008.10.020

DiStefano, C., \& Motl, R. W. (2009b). Self-esteem and method effects associated with negatively worded items: Investigating factorial invariance by sex. Structural Equation Modeling: A Multidisciplinary Journal, 16(1), 134-146. https:/ / doi.org/10.1080/10705510802565403

DiStefano, C., \& W., R. (2006). Further investigating method effects associated with negatively worded items on self-report surveys. Structural Equation Modeling: A Multidisciplinary Journal, 13(3), 440-464. https://doi.org/10.1207/s15328007sem1303_6

Farh, J. L., \& Cheng, B. S. (1997). An investigation of modesty bias in self-ratings of work performance among Taiwanese workers. Chinese Journal of Psychology, 39(2).

Fiske, D. (1982). Convergent-discriminant validation in measurements and research strategies. New Directions for Methodology of Social \& Behavioral Science, 12. https: / psycnet.apa.org/record / 1982-31614-001

Greenberger, E., Chen, C., Dmitrieva, J., \& Farruggia, S. P. (2003). Item-wording and the dimensionality of the Rosenberg Self-Esteem Scale: Do they matter? Personality and Individual Differences, 35, 1241-1254. https:/ / doi.org/10.1016/S0191-8869(02)00331-8

Hair, J., Black, W., Babin, B., \& Anderson, R. (2009). Multivariate data analysis. Prentice Hall. London.

Lindwall, M., Barkoukis, V., Grano, C., Lucidi, F., Raudsepp, L., Liukkonen, J., \& Thgersen-Ntoumani, C. (2012). Method effects: The problem with negatively versus positively keyed items. Journal of Personality Assessment, 94, 196-204. https:/ / doi.org/10.1080/00223891.2011.645936

Mangundjaya, W. L. H. (2013). Is there cultural change in the national cultures of Indonesia? in steering cultural dynamics. Steering the Cultural Dynamics, 59-68.

Marsh, H. W. (1996). Positive and negative global self-esteem: A substantively meaningful distinction or artifactors? Journal of Personality and Social Psychology, 70(4), 810-819. https:/ / doi.org/10. 1037/0022-3514.70.4.810

Marsh, H. W., Scalas, L. F., \& Nagengast, B. (2010). Longitudinal tests of competing factor structures for the Rosenberg Self-Esteem Scale: Traits, ephemeral artifacts, and stable response styles. Psychological Assessment, 22(2), 366-381. https://doi.org/10.1037/a0019225

Molt, R., \& Conroy, D. (2000). Social physique anxiety scale (spas). Psychobiology and Social Sciences, 32, 1007-1017. www.midss.ie 
Motl, R. W., \& DiStefano, C. (2002). Longitudinal invariance of self-esteem and method effects associated with negatively worded items. Structural Equation Modeling: A Multidisciplinary Journal, 9(4), 562-578. https://doi.org/10.1207/s15328007sem0904_6

Paramita, W. M., Permatasari, D. P., Rahajeng, U. W., Psikologi, P. S., \& Malang, U. B. (2014). Perbedaan identitas etnis pada remaja etnis jawa dan etnis tionghoa [differences in ethnic identity in javanese and chinese ethnic teenagers]. Universitas Brawijaya Malang.

Phinney, J. S. (1992). The multigroup ethnic identity measure. Journal of Adolescent Research, 7(2), 156-176. https://doi.org/10.1177/074355489272003

Pohl, S., Steyer, R., \& Kraus, K. (2007). Modelling method effects as individual causal effects. Journal of the Royal Statistical Society: Series A (Statistics in Society). https:/ / doi.org/10.1111/j.1467985x.2007.00517.x

Rodrigo, M. F., Molina, J. G., Losilla, J.-M., Vives, J., \& Tomás, J. M. (2019). Method effects associated with negatively and positively worded items on the 12-item general health questionnaire (GHQ-12): Results from a cross-sectional survey with a representative sample of catalonian workers. BMJ Open, 9(11), e031859. https://doi.org/10.1136/bmjopen-2019-031859

Tomas, J. M., \& Oliver, A. (1999). Rosenberg Self-Esteem Scale: Two factors or method effects. Structural Equation Modeling: A Multidisciplinary Journal, 6(1), 84-98. https : / / doi . org / 10.1080 / 10705519909540120

Tomás, J. M., Oliver, A., Galiana, L., Sancho, P., \& Lila, M. (2013). Explaining method effects associated with negatively worded items in trait and state global and domain-specific self-esteem scales. Structural Equation Modeling: A Multidisciplinary Journal, 20(2), 299-313. https: / / doi.org/10. 1080/10705511.2013.769394

Umaña-Taylor, A. J. (2004). Ethnic identity and self-esteem: Examining the role of social context. Journal of Adolescence, 27(2), 139-146. https:/ / doi.org/10.1016/j.adolescence.2003.11.006

Umaña-Taylor, A. J., \& Shin, N. (2007). An examination of ethnic identity and self-esteem with diverse populations: Exploring variation by ethnicity and geography. Cultural Diversity and Ethnic Minority Psychology, 13(2), 178-186. https://doi.org/10.1037/1099-9809.13.2.178

Vinet, L., \& Zhedanov, A. (2011). A 'missing' family of classical orthogonal polynomials. Journal of Physics A: Mathematical and Theoretical, 44(8), 085201. https://doi.org/10.1088/1751-8113/44/ $8 / 085201$

Widhiarso, W. (2016). Estimasi reliabilitas pengukuran dalam pendekatan model persamaan struktural [estimation of measurement reliability in the structural equation model approach]. Buletin Psikologi, 17(1). https://doi.org/10.22146/bpsi.11480

Widhiarso, W. (2017). Mengakomodasi efek metode dalam pengujian validitas konstruk melalui analisis faktor konfirmatori [accommodating the effect of the method in testing construct validity through confirmatory factor analysis]. Psikologia : Jurnal Psikologi, 1, 37. https: / / doi. org/10.21070/psikologia.v1i1.478 
Nada \& Marianti || Understanding the Method Effects

Wu, C.-H. (2008). An examination of the wording effect in the Rosenberg Self-Esteem Scale among culturally Chinese people. The Journal of Social Psychology, 148(5), 535-552. https:/ / doi.org/10. 3200/socp.148.5.535-552

Wu, Y., Zuo, B., Wen, F., \& Yan, L. (2016). Rosenberg Self-Esteem Scale: Method effects, factorial structure and scale invariance across migrant child and urban child populations in China. Journal of Personality Assessment, 99(1), 83-93. https://doi.org/10.1080/00223891.2016.1217420

Zeng, B., Wen, H., \& Zhang, J. (2020). How does the valence of wording affect features of a scale? the method effects in the undergraduate learning burnout scale. Frontiers in Psychology, 11. https: //doi.org/10.3389/fpsyg.2020.585179 